\title{
Forest edge creates small-scale variation in reproductive rate of sika deer
}

\author{
Tadashi Miyashita $\cdot$ Maki Suzuki $\cdot$ Daisuke Ando $\cdot$ \\ Go Fujita $\cdot$ Keiji Ochiai $\cdot$ Masahiko Asada
}

Received: 1 June 2007/ Accepted: 25 October 2007/Published online: 11 December 2007

(C) The Society of Population Ecology and Springer 2007

\begin{abstract}
Habitat edges are considered to have an important role in determining the abundance of deer in forest landscapes, but to our knowledge there are few lines of evidence indicating that forest edge enhances the vital rate of deer. We examined pregnancy of female sika deer in Boso peninsula, central Japan, and explored how forest edges, food availability in forests, and local population density influence the pregnancy rate of sika deer. Local deer density was estimated by the number of fecal pellets, and food availability in forests was estimated by combining GIS data of vegetation distribution and the relationship between vegetation biomass and local deer density. Forest edge length was also determined by GIS data. Model selection was performed with multiple logistic regression analyses using the AIC to find the best model for accounting for the observed variation in pregnancy rates of the deer. Multiple logistic regression analysis showed that the length of forest edge had a positive effect on the pregnancy rate of females, whereas food availability in forests and local deer density had little effect. This forest edge effect was detected in a 100-200-m radius from deer
\end{abstract}

Electronic supplementary material The online version of this article (doi:10.1007/s10144-007-0068-y) contains supplementary material, which is available to authorized users.

T. Miyashita $(\bowtie) \cdot$ M. Suzuki $\cdot$ D. Ando · G. Fujita

Laboratory of Biodiversity Science,

School of Agriculture and Life Sciences,

University of Tokyo, Tokyo 113-8656, Japan

e-mail: tmiya@es.a.u-tokyo.ac.jp

K. Ochiai · M. Asada

Natural History Museum and Institute,

Chiba, 995-2 Aoba, Chiba 260-8682, Japan captured locations, indicating that deer pregnancy is primarily determined by habitat quality within a 10-ha area. This result was confirmed by tracking females with GPS telemetry, which found that the core areas of the home range were less than 12 ha. The positive effect of edges and the lack of density dependence could be a result of high plant productivity in open environments that produces forages not depleted by high deer densities. Our results support the view that land management is the cause of the current problem of deer overabundance.

Keywords Cervus nippon - Density-dependence . Food availability $\cdot$ Habitat management . Landscape structure $\cdot$ Vital rate

\section{Introduction}

Recent studies have shown that deer populations have spatial structures comprising units that differ in densities and vital rates (Coulson et al. 1997; Focardi et al. 2002; Pettorelli et al. 2003; Zannese et al. 2006), most of which are formed by heterogeneous landscape structure. One of the important elements causing forest heterogeneity is the forest edges that abut clearcuts, farmlands, and roads, which provides abundant and high-quality foliage (e.g., Lyon and Jensen 1980; Alverson et al. 1988; Decalesta 1997). Several lines of evidence suggest that edges are high-quality habitats for deer; local population densities were higher (e.g., Wahlstrom and Kjellander 1995; Hemami et al. 2005), home range sizes were smaller (Kie et al. 2002; Said and Servanty 2005), and utilization rates by deer were higher than would be expected by random (e.g., Moe and Wegge 1994; Tufto et al. 1996; Lamberti et al. 2006) in edge habitats. However, preference for a particular habitat (or 
vegetation type) does not necessarily lead to a higher reproductive output. For instance, Juncus-dominated marsh was the highest ranked resource for red deer based on relative use versus availability, but it had little effect on reproductive success (McLoughlin et al. 2006). Although there is an increasing number of studies showing the linkage between habitat quality and individual reproductive output in deer (e.g., Conradt et al. 1999; Nilsen et al. 2004; Pettorelli et al. 2005; McLoughlin et al. 2006, 2007)), very few studies have demonstrated that higher utilization of forest edges by deer translates into increased reproductive output (but see McLoughlin et al. 2007). Examining the extent to which forest edges affect deer reproduction is crucial for predicting population dynamics and implementing appropriate management plans in forested landscapes.

The sika deer (Cervus nippon) population in the Boso peninsula, central Japan, has been increasing over the past 30 years and is becoming a serious threat to biodiversity and in forest ecosystems (Miyashita et al. 2004; Suzuki et al. 2007) as well as to agricultural activities (Chiba Prefecture 2004). The landscape of Boso peninsula is a mosaic of fine-scale elements including broadleaved forests, Japanese cedar plantations, and agricultural fields. Our previous work has documented that fecal nitrogen levels, a measure of food quality, were positively correlated with forest edge length within a landscape, yet negatively correlated with local deer density (Miyashita et al. 2007). Accordingly, aside from the landscape structure, local deer density is likely to affect reproduction of deer through food resource depression, as reported in other studies on deer (e.g., Gaillard et al. 2000; Focardi et al. 2002; Keyser et al. 2005; Stewart et al. 2005). To determine if such effects are manifested in the reproductive rate, we first analyzed factors determining the pregnancy rate in female sika deer, with particular attention to forest edges and food availability in the forest understory. Because we estimated food availability using the relationship between deer density and understory plant biomass, it mainly represents the effect of deer density through resource depression. Our analysis also revealed the spatial scale at which significant patterns in deer reproductive rate emerge. To demonstrate the validity of this scale, we examined the home range sizes of freeranging female deer using GIS telemetry. We expected that any positive influence of forest edge on pregnancy rate should be more pronounced at the female home range scale rather than at a larger landscape scale.

\section{Study area}

The Boso Peninsula is located in Chiba Prefecture, central Japan $\left(35^{\circ} \mathrm{N}, 140^{\circ} \mathrm{E}\right)$. This region has a warm temperate climate, with mean temperatures of $25^{\circ} \mathrm{C}$ in mid-summer and $5^{\circ} \mathrm{C}$ in mid-winter. Annual precipitation is 2,000$2,400 \mathrm{~mm}$, with almost no snowfall in winter. Broadleaved evergreen forests (Castanopsis sieboldii and Quercus spp.) and coniferous plantations (Cryptomeria japonica and Chamaecyparis obtusa) dominate the vegetation. The forest understory vegetation consists of evergreen shrubs (e.g., Aucuba japonica, Eurya japonica), forbs (e.g., Rubus buergeri), sedges, and various fern species.

Sika deer were once restricted to a small area of $40 \mathrm{~km}^{2}$. The population began to increase in the early 1970s, and its distribution has continued to expand, covering a current area of $440 \mathrm{~km}^{2}$ (Chiba Prefecture 2004). The deer density varies locally, with southern areas generally having higher densities ( $>20$ deer $\left./ \mathrm{km}^{2}\right)$.

\section{Methods}

\section{Deer pregnancy}

We examined the pregnancy status of female sika deer culled from mid-February to mid-March in 2005. Age and fetus presence were determined for 61 females that were obtained from a $340 \mathrm{~km}^{2}$ region that accounted for approximately three-fourths of the entire distribution area. Additionally, kidney fat index as determined by the ratio of fat mass and fat-free kidney mass multiplied by 100 (Riney 1955) was measured for 56 females to estimate deer condition. The culling location of each individual was recorded on a map $(1: 50,000)$. Deer age was determined by examining the annual layers in the tooth cementum ( $>2$ years old) (Scheffer 1950), and by the degree of replacement of milk teeth by permanent teeth $(0-2$ years old) (Ohtaishi 1980). For the data analysis, only two age classes (yearling and adult) were used because the sika deer is known to show stable age-specific pregnancy rates when becoming adult (Takatsuki 2006).

\section{Deer density index}

Distributions of deer fecal pellets were investigated during the winters (December-January) from 1996 to 2005, when fecal decomposition rates were low. The density of fecal pellets $[X$ (per 100 quadrats)] shows a high correlation with local deer density $\left[D\left(\mathrm{~km}^{-2}\right)\right]$ as estimated using a block counting method (Maruyama and Nakama 1983), creating the following relationship:

$D=0.76+0.079 X$

$\left(r^{2}=0.731, n=14, P<0.001\right.$; Chiba Prefecture 1998). Thus, the number of fecal pellets found on each census line can be regarded as an index of deer density. In 1996, a total 
of 92 transects (each $1 \mathrm{~km}$ long and $1.6 \mathrm{~km}$ apart) were placed to cover the entire distribution area of sika deer. Investigators counted all fecal pellets found within 200 quadrats along each transect; the quadrats were $1 \times 1 \mathrm{~m}$ and were placed at 5-m intervals. Approximately half of all transects were investigated each year alternately, except in 2005 when all transects were surveyed. We defined the deer density index (DDI, $\mathrm{m}^{-2} / \mathrm{year}$ ) of a line transect as the total number of fecal pellets found from 1996 to 2005 divided by the search area per transect $\left(200 \mathrm{~m}^{2}\right)$ and by census time. Because each transect was $1 \mathrm{~km}$ in length, we considered that the local density estimated by the DDI comprised the home ranges of several females (see "Results" section).

The distribution of the DDI across the whole area of the deer distribution was estimated at $1-\mathrm{km}$ resolutions, assuming that the DDI was at the geometric center of the $1 \mathrm{~km}$-mesh and represents the mean value of that mesh. The DDI at each mesh was calculated as the inverse distance weighted interpolation from the DDI data within $4 \mathrm{~km}$ of the mesh center.

Whether pellet counts are a reliable proxy for deer density has been heavily debated (e.g., Fuller 1991; Morellet et al. 2007). However, the spatial gradient of pellet densities of the Boso deer population was fairly stable in 8 years (see Electronic Supplementary Material $\mathrm{S} 1$ ). If the pellet count did not reflect local densities, such consistent patterns could not have been obtained. Thus, DDI appears to capture the spatial gradient of deer density successfully in our case study.

\section{Food availability}

We estimated food availability for deer based on the empirical relationships between the biomass of palatable plants and the DDI, as well as the vegetation classification map on GIS. First, we conducted two series of surveys of the forest-floor vegetation: "interior" and "edge" surveys. For the interior survey, we placed five quadrats $(2 \times 2 \mathrm{~m})$ in each of 30 cedar plantations and 35 broad-leaved forests that had varying deer densities and measured the coverage of palatable plants with heights of less than $2 \mathrm{~m}$ within each quadrat. The interior survey was conducted in February and September 2005. More detailed methods of this survey were described in Suzuki et al. (2007). The relationship between plant cover $(F \%)$ and DDI was described using a logistic equation (Suzuki et al. 2007):

$F=100\left\{1+\exp \left(-a_{0}-a_{1} \mathrm{DDI}\right)\right\}^{-1}$.

We converted plant coverage $(F \%)$ into dry biomass $\left(W, \mathrm{~g} / \mathrm{m}^{2}\right)$ by the following formula,
$W=0.25 F^{1.4} \quad\left(r^{2}=0.85, P<0.001\right)$.

This relationship was obtained by examining the projective cover and foliage dry biomass of palatable plants in 75 quadrats $(2 \times 2 \mathrm{~m})$.

For the edge survey, we established four sets of four quadrats $(1 \times 1 \mathrm{~m})$ inside the forest, with each set of quadrats located at $0,2,5$, and $10 \mathrm{~m}$ from the forest edge and measured the projective cover of palatable plants with a height of less than $2 \mathrm{~m}$. This survey was conducted in 14 cedar plantations and 16 broad-leaved forests in August 2006. We initially estimated the biomass of palatable plants $\left(W, \mathrm{~g} / \mathrm{m}^{2}\right)$ at each quadrat using Eq. 2 , and then fitted them to the following logistic equation,

$W=b_{0}\left\{1+\exp \left(b_{1} \mathrm{DFE}+b_{2} \mathrm{DDI}\right)\right\}^{-1}$,

where DFE (m) represents the distance from the forest boundary, implying that plant biomass decreases from the boundary to the forest interior. Parameters of both Eqs. 1 and 3 were estimated separately for conifer plantations and broad-leaved forests in summer and winter. We regarded the total cover of evergreen plants as the cover in winter. Regression analyses were performed using $R$ for Windows 2.2.0.

Next, we classified landscape elements of the Boso Peninsula into four categories (open habitats, coniferous plantations, broad-leaved forests and other) based on the most recent vegetation/land use map available on J-IBIS (Ministry of the Environment 2000). Major land-use changes after the last update of J-IBIS was corrected based on an ASTER image taken in March 2004 (Earth Remote Sensing Data Analysis Center 2004). The grid resolutions of the GIS analyses and satellite images were 5 and $15 \mathrm{~m}$, respectively. The area of conifer plantations and broadleaved forests were calculated for every $50-\mathrm{m}$ mesh, which was used for the plant biomass calculation.

The plant biomass in a 50-m mesh $\left(W_{50}\right)$ was calculated as:

$W_{50}=W_{i}+W_{e}$,

where $W_{i}$ and $W_{e}$ are the biomass in the interior parts ( $>10 \mathrm{~m}$ from the boundaries) and edges $(<10 \mathrm{~m}$ from the boundaries), respectively. $W_{i}$ was computed from Eqs. 1 and 2, whereas $W_{e}$ was calculated by integrating Eq. 3 for $0-10 \mathrm{~m}$ of DEF, given a value of DDI. These computations were made on ArcGIS 8.3 (ESRI Co. Ltd) with the help of Hawth's Tools for Spatial Analyst (Beyer 2004).

\section{Forest edge length}

We calculated the length of the forest edge that was likely to influence the reproductive rates of sika deer in our 
system, because this proved to be the only influential landscape variable determining food quality estimated by fecal nitrogen levels (Miyashita et al. 2007). The forest edge length was defined as the total length of forest perimeter abutting open habitats and roads with a width $>2 \mathrm{~m}$; this was calculated using the GIS data mentioned in the "Food availability" section.

\section{Home range}

Six females were caught in forested areas where deer densities were relatively high. Three females were equipped with telemetry collars (Lotek GPS-3300S, Ontario, Canada) in early summer (late June to early July), and another three females were equipped in late autumn (midNovember) of 2005. Animals tracked in the summer were located every $30 \mathrm{~min}$, and their collars were retrieved after 4 weeks using a self-drop-off system, whereas individuals tracked in the winter were located every hour and their collars were retrieved after 17 weeks.

\section{Data analysis}

\section{Factors determining pregnancy rate}

We performed multiple logistic regression analyses to detect factors influencing deer pregnancy rates. The dependent variable was the presence/absence of a fetus for each female, and the independent variables were forest edge length, summer or winter food availability, local deer density, and age (yearling vs. adult). Because deer density has a high correlation with food availability, they were not included in the same regression model. The spatial extent at which independent variables should be extracted is not clear, so we generated a buffer circle with a given radius $(100,200,300,400$, and $500 \mathrm{~m})$ around each location where females had been caught and then calculated forest edge length ( $\mathrm{m} / \mathrm{ha}$ ), food availability (vegetation biomass/ $\mathrm{m}^{2}$ ) in forests, and the DDI within the buffer area using ArcGIS. We performed model selection for the multiple logistic regressions using the Akaike Information Criterion (AIC). Based on the AIC we also computed Akaike weights $\left(w_{\mathrm{i}}\right)$, which represent the probabilities that model $i$ is the best model in the set of models considered. Additionally, we performed supplementary analyses separately for yearling and adult in the same way above, except that we used AICc for model selection criterion because of small sample sizes.

To assess the ability of the best model to discriminate between pregnant and non-pregnant females, we generated an ROC curve and calculated the area under the ROC curve
(AUC). AUC values that were $>0.7$ indicate an acceptable discrimination capacity (Hosmer and Lemeshow 2000).

To examine the difference in kidney fat index between females with and without a fetus, a two-way ANOVA was conducted using the presence/absence of a fetus and age (yearling vs. adult) as two factors.

\section{Home range}

The home range of deer was computed using 95 and $50 \%$ kernel isopleths (Worton 1989), using reference bandwidth (Worton 1995). These estimates were computed using the $R /$ adehabitat package (Calenge 2006).

To evaluate habitat preference by the deer, a habitat map of the home range area (MCP estimates) was produced using aerial photos taken in September 2003 and GIS software (ESRI ArcMap 8.3). The classification of habitats was the same as in food availability, except that forested areas within $5 \mathrm{~m}$ of the forest boundaries were also classified as grassland because of the high productivity of deer forage (Miyashita et al. 2007).

A deer preference index was calculated for each habitat type based on Aebischer et al. (1993). The preference index $\left(p_{i}\right)$ is the proportional use $\left(u_{i}\right)$ of the habitat type inversely weighted by the availability of the habitat type $\left(a_{i}\right)$ (Aebischer et al. 1993):

$p_{i}=1 /\left(\sum u_{j} / a_{j}\right) \times u_{i} / a_{i}$.

Here habitat availability was defined as the relative area of each habitat type within the home range, and proportional use was defined as the relative number of location points in each habitat type. A few location points for deer no. 6 fell on open water and were excluded from the analysis.

\section{Results}

Relationship between plant biomass and deer density

Deer density showed a strong negative effect on the coverage of palatable plants in the forest-floor vegetation, both during summer and winter, and in both the conifer and broad-leaved forests (Table 1, parameter $a_{1}$ ). The effect of deer was similar in broad-leaved forests and in conifer plantations, as revealed by the similar slope values (parameter $a_{1}$ ), but palatable plants were generally more abundant in conifer forests, as shown in the intercepts (parameter $a_{0}$ ).

After controlling for the effect of deer density, the biomass of palatable plants in summer showed a marked decrease with increasing distance from the forest 
Table 1 Estimates of parameters $a_{0}$ and $a_{1}$ in Eq. 2: $F(\%)=$ $100\left\{1+\exp \left(-a_{0}-a_{1} \mathrm{DDI}\right)\right\}^{-1}$

\begin{tabular}{lll}
\hline & $a_{0}$ & $a_{1}$ \\
\hline Summer & & \\
$\mathrm{CP}$ & $0.11 \pm 0.063 \dagger$ & $-1.19 \pm 0.07 * * *$ \\
$\mathrm{HF}$ & $-0.95 \pm 0.062^{* * *}$ & $-1.18 \pm 0.09^{* * *}$ \\
Winter & & \\
$\mathrm{CP}$ & $-0.41 \pm 0.085^{* * *}$ & $-1.49 \pm 0.11^{* * *}$ \\
$\mathrm{HF}$ & $-1.07 \pm 0.071^{* * *}$ & $-1.47 \pm 0.11^{* * *}$ \\
\hline
\end{tabular}

Parameters were estimated using logistic regression, respectively for each season (summer/winter) for conifer plantations $(C P)$ and hardwood forests $(H F)$

*** $P<0.001, \dagger P<0.1$

Table 2 Estimates of parameters in Eq. 3:

$W=b_{0}\left\{1+\exp \left(b_{1} \mathrm{DFE}+b_{2} \mathrm{DDI}\right)\right\}^{-1}$

\begin{tabular}{llll}
\hline \multicolumn{2}{l}{$b_{0}$} & $b_{1}$ & $b_{2}$ \\
\hline \multicolumn{2}{l}{ Summer } & & \\
$\mathrm{CP}$ & $362.76 \pm 42.17 * * *$ & $0.21 \pm 0.044 * * *$ & $1.36 \pm 0.21 * * *$ \\
$\mathrm{HF}$ & $216.72 \pm 18.27 * * *$ & $0.42 \pm 0.064 * * *$ & $0.77 \pm 0.13 * * *$ \\
Winter & & \\
$\mathrm{CP}$ & $96.88 \pm 19.13 * * *$ & $0.12 \pm 0.062 \dagger$ & $0.75 \pm 0.28 * *$ \\
$\mathrm{HF}$ & $62.41 \pm 10.91 * * *$ & $0.16 \pm 0.063 *$ & $1.31 \pm 0.41 * *$ \\
\hline
\end{tabular}

Parameters were estimated using non-linear least squares regression, respectively, for each season (summer/winter) for conifer plantations $(C P)$ and hardwood forests $(H F)$

$* P<0.05, * * P<0.01, * * * P<0.001, \dagger P<0.1$

boundaries. A similar, but weaker tendency was found in the winter (Table 2, parameter $b_{1}$ ).

Factors determining pregnancy rate

To explore the spatial extent at which independent variables could explain the pregnancy rates of sika deer, we show the model with the lowest AIC for each radius of buffer circle (Fig. 1) together with the null model (no variables). For all females combined, buffers with a radius of 100 and $200 \mathrm{~m}$ showed similar levels of the lowest AIC; these values were considerably lower than the AIC of the null model (Fig. 1a). However, the lowest AIC increased abruptly at $300 \mathrm{~m}$ and came close to the AIC of the null model. In buffers of 400 and $500 \mathrm{~m}$ radius, the null model had the lowest AIC. Accordingly, a spatial extent of 100 or $200 \mathrm{~m}$ appears to determine deer pregnancy. Supplementary analyses showed that yearlings and adults exhibited the lowest AIC in the buffer radius of 200 and $100 \mathrm{~m}$, respectively (Fig. 1b, c).

Table 3a shows the parameters of the five best models and the null model for the 200-m radius buffer (the best spatial extent). In all cases, "forest edge length" was always included and had an estimate that was approximately twice as large as its standard error. All other variables that are supposed to affect deer pregnancy, including food availability and deer density, exhibited estimated values that were equal to or lower than their standard errors, indicating that they had a very weak effect on the deer pregnancy rates. When analyzing separately for the age (Table 3b, c), forest edge always included in all models as well. Summer food was additionally included in the best model, but the sign was positive for yearlings and negative for adults. As the estimates of these variables were less than twice as large as their standard errors, they were not strong determinants for deer pregnancy.

Figure 2 shows the relationship between the length of forest edge and the pregnancy of females in the model with a 200-m radius buffer; this model had the lowest AIC among all possible models. Almost all deer inhabiting areas with more than $100 \mathrm{~m} /$ ha of forest edge became pregnant. The AUC value of the regression was 0.732 , indicating satisfactory discrimination capacity.

The kidney fat index of pregnant females was higher than that of non-pregnant females [mean (SE): 54.1 (3.6) vs. 33.4 (3.3); $\left.F_{1,55}=7.8, P=0.007\right]$, but it did not differ between ages $\left(F_{1,55}=0.9, P=0.358\right)$. The kidney fat index increased weakly with increasing length of the forest edge (Fig. 3; $r=0.229, P=0.081$ ). In particular, the lower

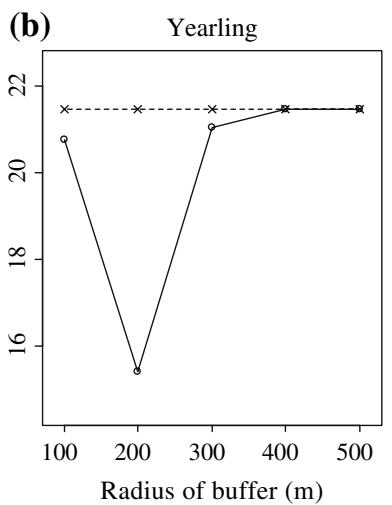

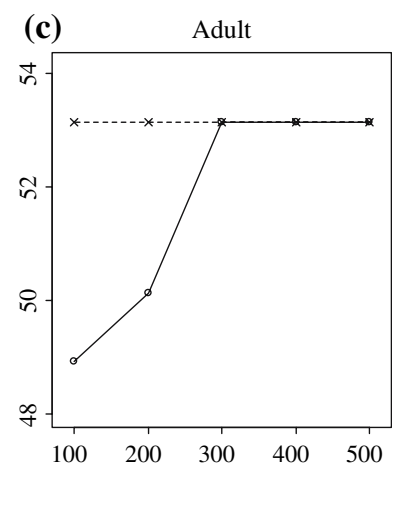

Fig. 1 The AIC values of the regression models explaining the pregnancy of female sika deer in each radius of buffer circle. Solid and dashed lines indicate AIC for the best model and the null model in each buffer size, respectively. For yearlings, AICc is used

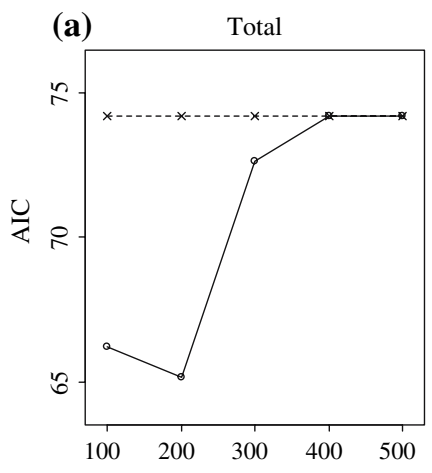


Table 3 Information-theoretic statistics and coefficients of selected variables for the top five (or four) models explaining the probability of pregnancy of female sika deer

\begin{tabular}{|c|c|c|c|c|c|c|c|c|c|c|c|c|}
\hline Model & AIC & $\Delta \mathrm{AIC}$ & $w_{i}$ & Intercept & Forest edge (km/ha) & \multicolumn{2}{|c|}{ Summer food } & \multicolumn{2}{|c|}{ Winter food } & \multicolumn{2}{|l|}{ DDI } & AGE \\
\hline \multicolumn{13}{|c|}{ (a) Total female (200-m radius buffer) } \\
\hline 1 & 65.158 & 0.00 & 0.288 & $-0.153(0.449)$ & $28.74(11.36)$ & \multicolumn{2}{|l|}{-} & \multicolumn{2}{|l|}{-} & \multicolumn{2}{|l|}{-} & - \\
\hline 2 & 66.423 & 1.27 & 0.153 & $-0.551(0.649)$ & $27.38(11.32)$ & \multicolumn{2}{|l|}{-} & \multicolumn{2}{|l|}{-} & \multicolumn{2}{|l|}{-} & $0.60(0.70)$ \\
\hline 3 & 66.581 & 1.42 & 0.141 & $-0.881(1.060)$ & $30.32(11.58)$ & \multicolumn{2}{|l|}{-} & \multicolumn{2}{|c|}{-} & \multicolumn{2}{|c|}{$0.006(0.007)$} & - \\
\hline 4 & 67.095 & 1.94 & 0.109 & $-0.059(0.581)$ & $29.13(11.44)$ & \multicolumn{2}{|l|}{-} & \multicolumn{2}{|c|}{$-0.77(3.06)$} & \multicolumn{2}{|l|}{-} & - \\
\hline 5 & 67.147 & 1.99 & 0.107 & $-0.208(0.696)$ & $28.58(11.47)$ & \multicolumn{2}{|c|}{$0.20(1.96)$} & \multicolumn{2}{|l|}{-} & \multicolumn{2}{|l|}{-} & - \\
\hline Null & 74.189 & 9.03 & 0.003 & $0.951(0.286)$ & - & - & & - & & - & & - \\
\hline Model & $\mathrm{AICc}$ & $\Delta \mathrm{AICc}$ & $w_{i}$ & Intercept & Forest edge (kn & ha) & Summe & food & Winter & food & DDI & \\
\hline (b) Yea & ling $(200-$ & $\mathrm{n}$ radius $\mathrm{b}$ & puffer) & & & & & & & & & \\
\hline 1 & 15.422 & 0.00 & 0.564 & $-6.664(4.405)$ & $132.09(81.30)$ & & $9.39(5$. & & - & & - & \\
\hline 2 & 17.258 & 1.84 & 0.225 & $-1.507(1.050)$ & 76.45 (46.77) & & - & & - & & - & \\
\hline 3 & 19.202 & 3.78 & 0.085 & $-2.802(1.749)$ & $81.47(45.96)$ & & - & & 6.28 & 80) & - & \\
\hline 4 & 20.284 & 4.86 & 0.050 & $-0.604(1.999)$ & $75.49(44.92)$ & & - & & - & & -0.008 & $(0.015)$ \\
\hline Null & 21.455 & 6.03 & 0.028 & $0.288(0.540)$ & - & & - & & - & & - & \\
\hline Model & AIC & $\Delta \mathrm{AIC}$ & $w_{i}$ & Intercept & Forest edge (kn & ha) & Summe & food & Winte & food & DDI & \\
\hline (c) Adu & $\left(100-\mathrm{m} \mathrm{r}^{2}\right.$ & adius buff & & & & & & & & & & \\
\hline 1 & 48.916 & 0 & 0.306 & $0.598(0.407)$ & $20.81(12.87)$ & & - & & - & & - & \\
\hline 2 & 49.565 & 0.649 & 0.221 & $1.397(0.826)$ & $26.74(15.68)$ & & -2.86 & $.51)$ & - & & - & \\
\hline 3 & 49.759 & 0.843 & 0.201 & $-0.659(1.232)$ & $23.69(13.62)$ & & - & & - & & 0.010 & (0.009) \\
\hline 4 & 49.837 & 0.921 & 0.193 & $1.52(0.685)$ & $25.16(14.81)$ & & - & & -4.53 & (4.37) & - & \\
\hline Null & 53.147 & 4.231 & 0.037 & $1.186(0.345)$ & - & & - & & - & & - & \\
\hline
\end{tabular}

Values in parentheses represent SE

DDI deer density index

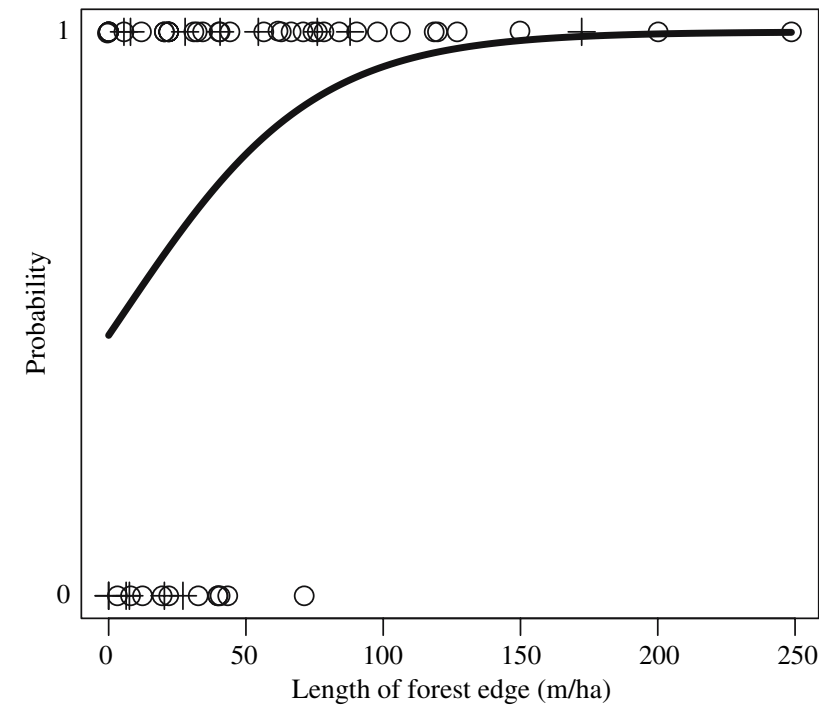

Fig. 2 The relationship between forest edge length and probability of pregnancy of sika deer (all females) in the model with a buffer circle of 200 -m radius. $\bigcirc$ : adults, + : yearlings limit of the KFI showed an increasing tendency with the forest edge length, which could be described by the 0.10 quantile regression line (Cade and Richards 1999); $Y=0.178 X+10.6$, where $Y$ and $X$ are the kidney fat index and length of forest edge, respectively. Nevertheless, the upper limit did not seem to change clearly, making a triangular shape of the data distribution on the $x-y$ plane.

Home range

The home range of each female deer was estimated using more than 200 location points, indicating adequate sample sizes for kernel estimates (Seaman et al. 1999). The deer exhibited small home-range sizes and core areas both in summer and winter (Table 4), with 95 and 50\% kernel estimates being less than 50 and 12 ha, respectively. The deer generally exhibited a higher preference for grassland compared to other landscape elements. Neither body mass nor age appeared to affect home range size and habitat use. 


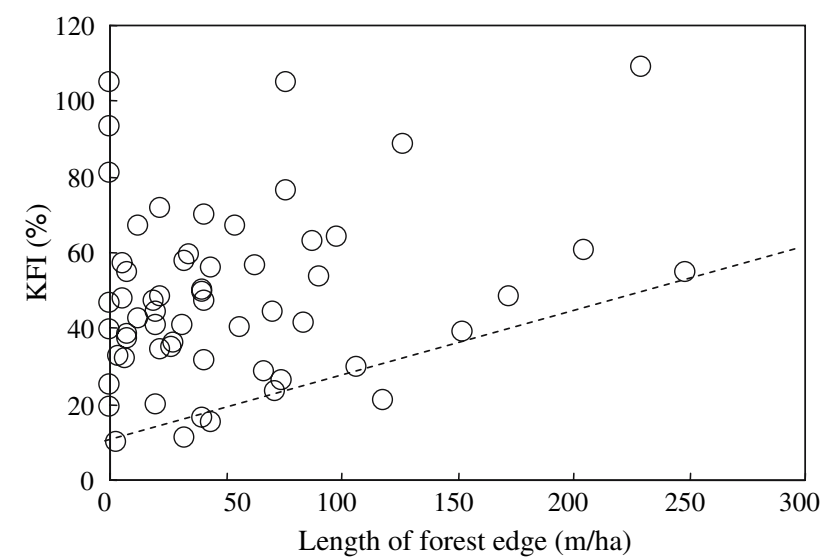

Fig. 3 Relationship between the length of forest edge and kidney fat index of sika deer. The broken line indicates 0.10 quantile regression

\section{Discussion}

Our most important finding is that increases in forest edge in a landscape led to an increased probability of pregnancy in female sika deer. This was demonstrated by the facts that (1) the best regression model included only the variable of forest edge length, and the difference in AICs between the best and null models was approximately nine, indicating substantial support for the best model (Burnham and Anderson 2002), (2) the estimate of forest edge length was more than twice as large as its standard error, whereas the estimates of other variables were equal to or smaller than their standard errors, and (3) the best model was able to satisfactorily discriminate between pregnant and nonpregnant females (AUC > 0.7). As revealed in previous studies, forest edges generally have higher productivity and larger biomass than forest-floor habitats (e.g., Lyon and Jensen 1980; Alverson et al.1988; Kremsater and Bunnell 1992; Rea 2003). In our study area, agricultural fields adjacent to forests harbor large amounts of plant material (Takada et al. 2002), and clearcuts and roadsides are also rich in plant biomass (unpubl. data). Furthermore, our previous work revealed higher levels of fecal nitrogen in a landscape with more forest edge (Miyashita et al. 2007). Thus, the high food availability in these habitats appeared to have enhanced nutritional condition, which then facilitated pregnancy rates in sika deer. This inference was supported by the positive correlation between the kidney fat index of females and the forest edge length in a landscape. Although edge length did not clearly affect the upper limit of nutritional condition, it did enhance the lower limit, which probably has increased the pregnancy rate of sika deer.

Although numerous studies have demonstrated the role of edge habitats on home range size (Kie et al. 2002; Said and Servanty 2005), habitat use (e.g., Moe and Wegge 1994; Tufto et al. 1996; Lamberti et al. 2006), and local densities (e.g., Wahlstrom and Kjellander 1995; Hemami et al. 2005) of deer, to our knowledge, there is only one other study that provided evidence of the importance of edge habitat on deer reproduction. McLoughlin et al. (2007) recently showed a positive association between lifetime reproductive success of female roe deer and home ranges containing forest edges (meadows and road). The striking similarity of the two results is probably due to the sedentary nature common to sika deer and roe deer. The home range size of sika deer in our study area was only 20 $50 \mathrm{ha}$, which is similar to the home range size of roe deer in European countries (e.g., Said and Servanty 2005; Focardi et al. 2006; Lamberti et al. 2006). Thus, fine-scale variation in habitat quality derived from the sedentary nature of sika deer and roe deer is likely to have caused a strong association between the length of forest edge and reproductive output. Social factors such as the high site fidelity of females may be responsible for the sedentarity (Porter et al. 1991, 2004; Pettorelli et al. 2001).

It is noteworthy that the spatial extent that appears to determine the deer pregnancy rate is approximately 10 ha or less because the regression model with a buffer radius of $200 \mathrm{~m}$ around the capture point of deer displayed the

Table 4 Home range size and habitat preference index of female deer estimated by GPS telemetry

\begin{tabular}{|c|c|c|c|c|c|c|c|c|c|c|c|}
\hline \multirow[t]{2}{*}{ Individual no. } & \multirow[t]{2}{*}{ Period } & \multirow[t]{2}{*}{ No. of locations } & \multirow[t]{2}{*}{ Body mass $(\mathrm{kg})$} & \multirow[t]{2}{*}{ Age } & \multicolumn{2}{|c|}{ Home range (ha) } & \multicolumn{5}{|c|}{ Preference index } \\
\hline & & & & & $95 \%$ kernel & $50 \%$ kernel & $\mathrm{CP}$ & $\mathrm{HF}$ & GL & $\mathrm{RD}$ & $\mathrm{RE}$ \\
\hline 1 & Summer & 498 & 30.5 & 1 & 23.1 & 3.5 & 0.21 & 0.03 & 0.37 & 0.26 & 0.13 \\
\hline 2 & Summer & 202 & 32.5 & $4-5$ & 17.8 & 3.2 & 0.49 & 0.26 & 0.25 & 0.00 & - \\
\hline 3 & Summer & 220 & 43 & $5-6$ & 20.9 & 4.8 & 0.15 & 0.08 & 0.50 & 0.26 & - \\
\hline 4 & Winter & 747 & 43.5 & 6 & 44.5 & 11.9 & 0.07 & 0.11 & 0.18 & 0.23 & 0.40 \\
\hline 5 & Winter & 317 & 38.5 & $8-10$ & 25.0 & 4.7 & 0.22 & 0.09 & 0.44 & 0.25 & - \\
\hline 6 & Winter & 743 & 41 & $8-10$ & 47.1 & 11.9 & 0.03 & 0.22 & 0.36 & 0.39 & - \\
\hline Mean & & & & & 29.7 & 6.7 & 0.20 & 0.13 & 0.35 & 0.23 & 0.27 \\
\hline SE & & & & & 5.2 & 1.7 & 0.07 & 0.04 & 0.05 & 0.05 & 0.08 \\
\hline
\end{tabular}

$C P$ conifer plantation, $H F$ hardwood forest, $G L$ grassland, $R D$ road, $R E$ residential area, - no residential area in home range 
lowest AIC, followed by the model with a $100-\mathrm{m}$ radius buffer. It seems unlikely that spatial extents larger than $300 \mathrm{~m}$ were effective because models with the lowest AICs were null models in those extents. The effective spatial extent of $200 \mathrm{~m}$ was supported by the home range size of females as estimated using GPS telemetry. Although home range estimates by $95 \%$ kernel methods were larger than this extent (20-50 ha vs. 10 ha), the $50 \%$ kernel estimate was equivalent to or smaller than this (3-12 ha vs. 10 ha). These results suggest that the pregnancy of sika deer is largely determined by the habitat quality of the core area of its home range and that fine-scale variability in reproductive rates is ascribed to the small range size coupled with fine-scale landscape heterogeneity in this system.

Contrary to our expectation, we found no evidence for a density-dependent reduction in deer pregnancy as estimated by food availability in forests (a function of local density) and local density per se, despite the fact that food availability in forests clearly decreased with increasing deer density. This is probably because food availability in open environments is much higher than that in the forest interior and is not depleted by deer foraging due to its high productivity. This suggests that vegetation in open environments provides ample food for deer, and the heavy pressure on forest vegetation by deer did not result in a negative feedback to deer reproduction. The large amount of annual rainfall $(2,000-2,400 \mathrm{~mm})$ and warm winter temperature $\left(5^{\circ} \mathrm{C}\right)$ appear to be responsible for the high productivity in our study region. An alternative explanation for the absence of density dependence could be that the range of deer densities in our sample was not large enough to detect the negative effects of density. This is unlikely, however, because the range of local deer densities was 220 individuals $/ \mathrm{km}^{2}$. Other studies also revealed that sika deer do not exhibit clear density-dependence unless they reach extremely high population densities leading to population eruption (Putman and Clifton-Bligh 1997; Kaji et al. 2004).

Our results have important implications for the management of sika deer. If deer depend on forest-floor vegetation for their food, the population density should be regulated in a density-dependent manner, and chronic high densities should not be possible. Actually, however, sika deer in this system appear to be sustained by food resources from open environments outside the forest interior, with no obvious decreases by consumption ("donor-controlled" consumer-resource interaction, e.g., Polis and Strong 1996). This may create continuous negative effects on forest ecosystems even after forest-floor vegetation is severely damaged. This is likely to cause soil erosion and the deterioration of ecosystem function through changes in the physical and chemical properties of the soil (Binkley et al. 2003; Furusawa et al. 2003; Danell et al. 2006). To prevent such ecosystem change, we should increase the awareness of local governments and stakeholders as to how change in land use could lead to deer overabundance and associated negative effects on forests. Although this scenario has long been advocated by many researchers (white-tailed deer: Alverson et al. 1988, Decalesta 1997; black-tailed deer: Kremsater and Bunnell 1992; mule deer: Kie et al. 2002; muntjac: Hemami et al. 2005), it has now become more persuasive in light of our results. We would like to re-emphasize the statement by Schmitz and Sinclair (1997) that the problem of deer overabundance may be attributed to land management issues, rather than the result of a lack of population management.

Acknowledgments The field survey was supported by the Tokyo University Forest in Chiba. We thank K. Kaji and J.-M. Gaillard for helpful comments on the manuscript and Y. G. Baba, T. T. Yamanoi, M. Kobayashi, S. Harada, H. Horii, Y. Shimizu, M. Takada, K. Tokita, and S. Tomoda for assistance in the field surveys. This study was supported by the Environmental Technology Development Fund (no. 60029), Ministry for the Environment, Japan.

\section{References}

Aebischer NJ, Robertson PA, Kenward RE (1993) Compositional analysis of habitat use from animal radio-tracking data. Ecology 74:1313-1325

Alverson WS, Waller DM, Solheim SL (1988) Forests too deer: edge effects in northern Wisconsin. Conserv Biol 2:348-358

Beyer HL (2004) Hawth's analysis tools for ArcGIS, Version 2. http://www.spatialecology.com/htools

Binkley D, Singer F, Kayae M, Rochelle R (2003) Influence of elk grazing on soil properties in Rocky Mountain National Park. For Ecol Manage 185:239-247

Burnham KP, Anderson DR (2002) Model selection and multimodel inference: a practical information-theoretic approach, 2nd edn. Springer, New York

Cade BS, Richards JD (1999) User manual for BLOSSOM statistical software. U.S. Geological Survey, Fort Collins Science Center, Colorado

Calenge C (2006) The adehabitat package. http://cran.r-project.org/ src/contrib/Descriptions/adehabitat.html

Chiba Prefecture (1998) Science Report on the Management of sika deer on Boso Peninsula (in Japanese). Chiba Prefecture, Chiba, Japan

Chiba Prefecture (2004) Science Report on the Management of sika deer on Boso Peninsula (in Japanese). Chiba Prefecture, Chiba, Japan

Conradt L, Clutton-Brock TH, Guinness FE (1999) The relationship between habitat choice and lifetime reproductive success in female red deer. Oecologia 120:218-224

Coulson T, Albon S, Guiness F, Pemberton J, Clutton-Brock T (1997) Population substructure, local density, and calf winter survival in red deer (Cervus elaphus). Ecology 78:852-863

Danell K, Bergstrom R, Duncan P, Pastor J (2006) Large herbivore ecology, ecosystem dynamics and conservation. Cambridge University Press, Cambridge

Decalesta DA (1997) Deer and ecosystem management. In: McShea WJ, Underwood HB, Rappole JH (eds) The science of overabundance. Smithsonian Books, Washington, pp 267-279 
Earth Remote Sensing Data Analysis Center (2004). ASTER User's Guide. http://www.science.aster.ersdac.or.jp/en/documnts/users_ guide/index.html

Focardi S, Pelliccioni ER, Petrucco R, Toso S (2002) Spatial patterns and density dependence in the dynamics of a roe deer (Capreolus capreolus) population in central Italy. Oecologia 130:411-419

Focardi S, Aragno P, Montanaro P, Riga F (2006) Inter-specific competition from fallow deer Dama dama reduces habitat quality for the Italian roe deer Capreolus capreolus italicus. Ecography 29:407-417

Fuller TK (1991) Do pellet counts index white-tailed deer numbers and population change? J Wildl Manage 55:393-396

Furusawa H, Miyanishi H, Kaneko S, Hino T (2003) Movement of soil and litter on the floor of a temperate mixed forest with an impoverished understory grazed by deer (Cervus nippon centralis). J Jpn For Soc 85:318-325

Gaillard J-M, Festa-Bianchet M, Yoccoz NG, Loison A, Toigo C (2000) Temporal variation in fitness components and population dynamics of large herbivores. Annu Rev Ecol Syst 31:367-393

Hemami M-R, Watkinson AR, Dolman PM (2005) Population densities and habitat associations of introduced muntjac Muntiacus reevesi and native roe deer Capreolus capreolus in a lowland pine forest. For Ecol Manage 215:224-238

Hosmer DW, Lemeshow S (2000) Applied logistic regression. Wiley, New York

Kaji K, Okada H, Yamanaka M, Matsuda H, Yabe T (2004) Irruption of a colonizing sika deer population. J Wildl Manage 68:889899

Keyser PD, Guynn DC, Hill HS (2005) Density-dependent recruitment patterns in white-tailed deer. Wildl Soc Bull 33:222-232

Kie JG, Bowyer RT, Nicholson MC, Boroski BB, Loft ER (2002) Landscape heterogeneity at differing scales: effects on spatial distribution of mule deer. Ecology 83:530-544

Kremsater LL, Bunnell FL (1992) Testing responses to forest edges: the example of black-tailed deer. Can J Zool 70:2426-2435

Lamberti P, Mauri L, Merli E, Dusi S, Apollonio M (2006) Use of space and habitat selection by roe deer Capreolus capreolus in a Mediterranean coastal area: how does woods landscape affect home range? J Ethol 24:181-188

Lyon LJ, Jensen CE (1980) Management implications of elk and deer use of clear-cut in Montana. J Wildl Manage 44:352-362

Maruyama N, Nakama S (1983) Block count method for estimating serow populations. Jpn J Ecol 33:243-251

McLoughlin PD, Boyce MS, Coulson T, Clutton-Brock T (2006) Lifetime reproductive success and density-dependent, multivariable resource selection. Proc R Soc Lond B 273:1449-1454

McLoughlin PD, Gaillard J-M, Boyce MS, Bonenfant C, Messier F, Duncan P, Delorme D, Moorter B, Said S, Klein F (2007) Lifetime reproductive and composition of the home range in a large herbivore. Ecology (in press)

Ministry of the Environment (2000) Japan Integrated Biodiversity Information System (J-IBIS). http://www.biodic.go.jp/index_e. html

Miyashita T, Takada M, Shimazaki A (2004) Indirect effects of herbivore by deer reduce abundance and species richness of web spiders. Ecoscience 11:74-79

Miyashita T, Suzuki M, Takada M, Fujita G, Ochiai K, Asada M (2007) Landscape structure affects food quality of sika deer (Cervus nippon) evidenced by fecal nitrogen levels. Popul Ecol 49:185-190

Moe SR, Wegge P (1994) Spacing behaviour and habitat use of axis deer (Axis axis) in lowland Nepal. Can J Zool 72:1725-1744

Morellet N, Gaillard J-M, Hewison AJM, Ballon P, Boscardin Y, Duncan P, Klein F, Maillard D (2007) Indicators of ecological change: new tools for managing populations of large herbivores. J Anim Ecol 44:634-643

Nilsen EB, Linnell JDC, Andersen R (2004) Individual access to preferred habitat affects fitness components in female roe deer Capreolus capreolus. J Anim Ecol 73:44-50

Ohtaishi N (1980) Determination of sex, age and death-season of recovered remains of sika deer (Cervus nippon) by jaw and tooth-cement. Archaeol Nat Sci 13:51-74 (In Japanese with English summary)

Pettorelli N, Dray S, Gaillard J-M, Chessel D, Duncan P, Illius A, Guillon N, Klein F, Van Laere G (2003) Spatial variation in springtime food resources influences the winter body mass of roe deer fawns. Oecologia 137:363-369

Pettorelli N, Gaillard JM, Duncan P, Ouellet J-P, Van Laere G (2001) Population density and small-scale variation in habitat quality affect phenotypic quality in roe deer. Oecologia 128:400-405

Pettorelli N, Gaillard J-M, Yoccoz NG, Duncan P, Maillard D, Delorme D, Van Laere G, Toigo C (2005) The response of fawn survival to changes in habitat quality varies according to cohort quality and spatial scale. J Anim Ecol 74:972-981

Polis GA, Strong DR (1996) Food web complexity and community dynamics. Am Nat 147:813-846

Porter WF, Mathews NE, Underwood HB, Sage RW, Behrend DF (1991) Social organization in deer: implications for localized management. Environ Manage 15:809-814

Porter WF, Underwood HB, Woodard JL (2004) Movement behaviour, dispersal, and the potential for localized management of deer in a suburban environment. J Wildl Manage 68:247-256

Putman RJ, Clifton-Bligh JR (1997) Age-related body weight, fecundity and population change in a south Dorset sika population (Cervus nippon); 1985-1993. J Nat Hist 31:649-660

Rea RV (2003) Modifying roadside vegetation management practices to reduce vehicular collisions with moose Alces alces. Wildl Biol 9:81-91

Riney T (1955) Evaluating condition of free-ranging red deer (Cervus elaphus), with special reference to New Zealand. N Z J Sci Technol 36:429-463

Said S, Servanty S (2005) The influence of landscape structure on female roe deer home-range size. Landsc Ecol 20:1003-1012

Scheffer VB (1950) Growth layers on the teeth of pinnipedia as an indication of age. Science 112:309-311

Schmitz OJ, Sinclair ARE (1997) Rethinking the role of deer in forest ecosystem dynamics. In: McShea WJ, Underwood HB, Rappole JH (eds) The science of overabundance. Smithsonian Books, Washington, pp 201-223

Seaman DE, Millspaugh JJ, Kernohan BJ, Brundige GC, Raedeke KJ, Gitzen RA (1999) Effects of sample size on kernel home range estimates. J Wildl Manage 63:739-747

Stewart KM, Bowyer RT, Dick BL, Johnson BK, Kie JG (2005) Density-dependent effects on physical condition and reproduction in North American elk: an experimental test. Oecologia 143:85-93

Suzuki M, Miyashita T, Kabaya H, Ochiai K, Asada M, Tange T (2007) Deer density affects ground-layer vegetation differently in conifer plantations and hardwood forests on the Boso Peninsula, Japan. Ecol Res. doi:10.1007/s11284-007-0348-1

Takada M, Asada M, Miyashita T (2002) Cross-habitat foraging by sika deer influences plant community structure in a forestgrassland landscape. Oecologia 133:389-394

Takatsuki S (2006) Ecological history of sika deer. University of Tokyo Press, Tokyo (In Japanese with English summary)

Tufto J, Andersen R, Linnell J (1996) Habitat use and ecological correlates of home range size in a small cervid: the roe deer. $\mathrm{J}$ Anim Ecol 65:715-724

Wahlstrom LK, Kjellander P (1995) Ideal free distribution and natal dispersal in female roe deer. Oecologia 103:302-308 
Worton BJ (1989) Kernel methods for estimating the utilization distribution in home-range studies. Ecology 70:164-168

Worton BJ (1995) Using Monte Carlo simulation to evaluate kernelbased home range estimators. J Wildl Manage 59:794-800
Zannese A, Morellet N, Targhetta C, Culton A, Fuser S, Hewison AJM, Ramanzin M (2006) Spatial structure of roe deer populations: toward defining management units at a landscape scale. J Appl Ecol 43:1087-1097 